\title{
Decision Support System Design Model for Choosing Effective Learning Method in Higher Education Institution
}

\author{
Trisna Febriana $^{1 *}$ and Arif Budiarto ${ }^{2}$ \\ ${ }^{1}$ Information Systems Department, School of Information Systems, Bina Nusantara University \\ Jakarta 11480, Indonesia \\ ${ }^{2}$ Computer Science Department, School of Computer Science, Bina Nusantara University \\ Jakarta 11480, Indonesia \\ Email: ${ }^{1}$ trisna.febriana@gmail.com, ${ }^{2}$ abudiarto@binus.edu
}

\begin{abstract}
In an educational institution, especially higher education, producing qualified graduates is the highest priority achievement. The quality of the graduates is highly dependent on the applied learning method. However, sometimes universities have difficulty in determining appropriate learning for their students. Determination of this decision requires a tool that can facilitate decisionmakers in analyzing all the considerations in choosing decisions. Another challenge is when the decision is shared among multiple stakeholders with equal contribution. It consequently creates a need for a mechanism that can provide an equal contribution for each stakeholder. The research tries to create a model to design a tool that can determine the decisions that need to be taken. This model is built with the Multi-Criteria Decision Analysis (MCDA) approach. MCDA is selected because it can be implemented in a collaborative ecosystem where multiple stakeholders are involved. Then, a literature study is conducted to determine the attributes and decision-making parameters. In addition, the primary data derived from interviews to a total of 40 respondents consisting of students, lecturers, and staff are taken into consideration to complete the literature study. The literature review and interview output are then translated to some parameters that influence an effective learning system. The result shows that this model can be used as a reference in developing a web-based application as an implementation of MCDA.
\end{abstract}

Index Terms-Decision Support System, Effective Learning Method, Higher Education

\section{INTRODUCTION}

$\mathbf{I}$ $\mathrm{N}$ education, especially in universities, producing qualified graduates is a must and a challenge to be achieved. It consequently makes the universities focus on designing a good quality learning method and

Received: Aug. 31, 2020; received in revised form: Aug. 10, 2021; accepted: Aug. 10, 2021; available online: Aug. 30, 2021. *Corresponding Author content. A learning system is a unity of the components to support the quality of learning, among other factors such as educators, learners, facilities, infrastructure, and environmental factors. The competence of the educator includes the ability to master all these factors [1].

Then, the educator becomes a facilitator to assist students in achieving learning objectives. Learning objectives are several learning outcomes that students have done learning actions including new knowledge, skills, and attitudes expected to be achieved [2]. Another factor is the characteristics of learners in following the learning process. One's learning type is divided into three things: visual, auditory, and kinesthetic [3]. Meanwhile, the facilities, infrastructure, and environmental factors can be seen from the supporting infrastructure in the learning process. Infrastructure greatly affects the academic achievement of learners [4].

A lecturer should understand the overall factors that influence the success of the learning process. Success in achieving learning objectives should also be implemented with appropriate strategies or learning methods. Appropriate learning methods should accommodate all characteristics of learners and adjust the availability of infrastructure and the environment.

With such complex factors that influence the decision to choose the right learning method, it will be difficult for the lecturer to determine the strategy or learning method that will be applied in the teaching and learning process. One tool often used in decision-making is the Multi-Criteria Decision Analysis (MCDA) [5].

MCDA is a tool that can support the decisionmaking process based on some criteria that have the potential to create conflict. It creates an equal contribution for each party involved in the decisionmaking process. In general, MCDA is used in decision- 
Cite this article as: T. Febriana and A. Budiarto, "Decision Support System Design Model for Choosing Effective Learning Method in Higher Education Institution", CommIT (Communication \& Information

Technology) Journal 15(2), 105-112, 2021.

making in the public sector [6, 7]. In education, a lecturer becomes the decision holder in determining the strategy or learning method. Meanwhile, the university is responsible for creating a learning system that can provide an effective and comfortable environment for the students. Therefore, a tool is needed to facilitate all stakeholders in determining appropriate learning methods by adopting the concept of MCDA.

\section{LiterATURE REVIEW}

\section{A. Learning Style}

The type of learning is the characteristics and preferences or individual choice to gather information, interpret, organize, respond, and think of the information received [8]. Then, learning types can be divided into three approaches [3]. First, a visual man means that the learner will optimally absorb information by reading or seeing. Second, there is a human auditory. The information coming through what the learner hears will be absorbed optimally. Third, a kinesthetic man shows that the learner will be very happy and quick to understand if the information that must be absorbed is first "exemplified" or imagine others doing things that will be learned.

Moreover, to improve learning outcomes, several learning strategies can be undertaken and adapted to the learning type of learners [9] as follows.

1) Visual

- Encourage visual learners to create many symbols and images in their notes.

- Use paper with colored writing.

- Encourage learners to describe the information they receive using mind maps, tables, graphs, and diagrams to deepen their understanding of the information.

- Provide an overview/outline of each subject matter delivered by giving a blank space to add notes.

- Use a language that can create a visualization in the learners.

2) Auditory

- Use vocal variations (rhythm, volume, and intonation) when delivering learning materials.

- Use the termination by asking the learner to repeat the key concepts that have been learned.

- Encourage each learner to create abbreviations to make it easier to memorize concepts.

- Make the material easier to remember by turning it into a well-known song or melody.

- Encourage learners to record important information to be heard repeatedly.

\section{3) Kinesthetic}

- Use the tools at the time of teaching to generate curiosity and emphasize key concepts.

- Use concept simulation so that each learner can experience it by himself/herself.

- Demonstrate every taught concept and allow every learner to try to learn it gradually.

- Conduct short simulations to help the learner understand the material that is studied.

\section{B. Decision Support System (DSS)}

A Decision Support System (DSS) is a computerbased information system combining models and data to support decision-makers in solving semistructured problems or dependency problems involving deep users [10]. Here are characteristics of decisionmaking [11]:

1) It supports decision-making, especially in semistructured and structured situations, including human judgment and computerized information.

2) It supports all materials from top executives to line managers.

3) It supports individuals and groups. Unstructured problems often require individual involvement from different departments and organizational levels or even from other organizations.

4) It supports independent and sequential decisions. Decisions can be made once, multiple times, or over and over (in the same interval).

5) It is supported in all phases of the decisionmaking process (intelligent, design, choice, and implementation).

6) It supports various processes and decision-making styles.

7) Decision-making process should be able to accommodate changes. So, DSS can be flexible for users to add, delete, merge, modify, or rearrange basic elements. It can also be modified to solve other similar problems.

8) User-friendly, powerful graphical capabilities, and interactive machine interfaces with a single language experience can greatly increase the effectiveness of DSS. There are more web-based SPK applications.

9) It increases the effectiveness of decision-making (accuracy, timeliness, quality) compared to efficiency.

10) It specifically emphasizes supporting decisionmaking, not replaces.

11) End users can develop and modify the system.

12) Models are used to analyze decision-making situations. 
Cite this article as: T. Febriana and A. Budiarto, "Decision Support System Design Model for Choosing Effective Learning Method in Higher Education Institution", CommIT (Communication \& Information Technology) Journal 15(2), 105-112, 2021.

\begin{abstract}
13) Access is provided for various data sources, formats, and types.

14) It can be used as a standalone tool and integrated internally and externally using network and web technologies.
\end{abstract}

\section{Related works}

Some previous research related to decision-making systems with the concept of MCDA will be elaborated to corroborate the reasons for choosing this topic. The selected previous research is certainly the most relevant concerning the application of the MCDA concept in various fields.

The first one is research on the application of MCDA on the selection of class facilities for universities in Brazil [12]. In this research, the authors use a submethod called the analytic hierarchy process, which is part of MCDA. Respondents in this study include college managerial teams, lecturers, and students. These three types of the informant will provide data for MCDA analysis. However, the research does not include the creation of applications that can help to implement the MCDA concept but only uses spreadsheet documents. The example raised in the research is the selection of the right chair for the class. There are four types of seats that are evaluated using four criteria. In the end, one type of chair is chosen. A chair with a table for one person is the highest-rated option. Then, it is recommended in the new classroom development.

The next research is the application of MCDA in the assessment of sustainable agriculture [13]. The research is conducted in a coastal area of Bangladesh. The method used in the application of MCDA is the method of elimination. This method is used to minimize the giving of a less objective value. The rules of value assignment are based on existing standard rules. The research is the first in applying the method of elimination in agriculture. Criteria used in the assessment of existing agricultural systems are economical, environmental, and social aspects. The disadvantage of this elimination method is the possibility of missing the original criteria affecting the final judgment.

The last research to be addressed is the application of MCDA used in spatial data processing [14]. Spatial data used is open source. The research also builds web-based applications that can process existing spatial data and then process it with the MCDA method to provide decision support related to spatial data. The case study is about the application of spatial data in natural disaster management. The research exemplifies how to provide an MCDA based application and use open-source data that can be accessed by various stakeholders in policy or decision making.

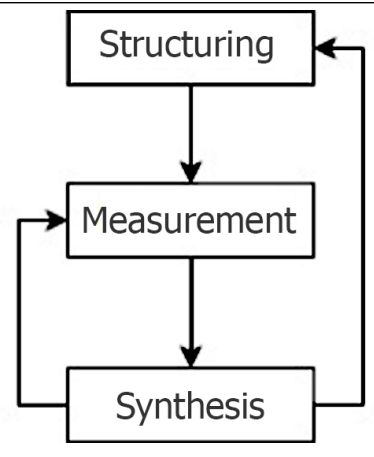

Fig. 1. Multi-Criteria Decision Analysis (MCDA) steps.

\section{RESEARCH MethoD}

The research illustrates how a lecturer can make decisions in applying learning methods in the classroom using the MCDA method. MCDA is a method that can help a decision-maker in deciding what to take [15]. With this method, a decision-maker can evaluate, prioritize, and ultimately determine the one that best fits the various criteria [16]. There are several aliases of this method, including Multiple Criteria Decision Making (MCDM), Multi-Attribute Decision Analysis (MADA), or Single Participant-Multiple Criteria Decision Making (SPMC) [17].

By using the MCDA method, the researchers can perform a ranking system against all existing alternatives to choose one of the most appropriate alternatives [7]. Actually, in daily life, people often use this method. In many cases, such as choosing items to buy or determining to move to a new place, people unconsciously use the MCDA method. In determining decisions for such cases, the researchers will look for the various criteria or considerations that help to decide the best option.

Many techniques are often used in applying MCDA. There are the Multiple-Attribute Utility Theory (MAUT) and Analytic Hierarchy Process (AHP) [18, 19]. With so many techniques in implementing the MCDA, it provides many options for determining the most effective decision-making model. MCDA is a method that can be applied to all fields, including in education. Therefore, this method will be used in this research to support the making of a decisionmaking system in education in selecting appropriate learning methods with various criteria. MCDA method is done in three main steps: structuring, measurement, and synthesis [12]. The MCDA step is described in Fig. 1.

At the structuring stage, there is an identification of decision objectives regarding learning methods that are often done by lecturers in the classroom, criteria that 
Cite this article as: T. Febriana and A. Budiarto, "Decision Support System Design Model for Choosing Effective Learning Method in Higher Education Institution", CommIT (Communication \& Information Technology) Journal 15(2), 105-112, 2021.

affect the method of learning, and alternative methods of learning. Then, the measurement stage will establish scores for criteria and alternative learning methods. Last, the synthesis stage concludes the MCDA, which allows changes in the structure and scores generated from the previous steps.

When MCDA is used for decision-making in a group, it helps groups to talk about their decisionmaking processes (issues to be solved) in a way that allows them to consider the important values. It also provides a unique ability for people to consider and talk about complex exchanges among alternatives. As a result, it helps people to think, rethink, ask, adjust, decide, rethink some more, test, adjust, and ultimately decide. MCDA consists of five components: purpose of decision making, decision-makers or decision-making groups, alternative decision, evaluation criteria, and results or consequences associated with alternative combinations.

The decision-making process using the MCDA concept will pass through seven stages. It includes determining decision-making attributes, determining the parameters of all decision-makers, building a decisionmaking framework, creating a ranking for all alternatives, parameter weighting, determining scores for each alternative, and determining final decisions. The research will only cover the first to the third stages. In the first and second stages, namely in determining the attributes and parameters of decision-making, the researchers conduct a comprehensive literature study of the learning method theory to determine attributes and parameters. Then, the third stage, which is the formation of a decision-making framework, includes primary data in the form of interview results. The resulting framework will be following the actual situation of the population taken.

The primary data used in preparing attributes and decision-making parameters are taken through a brief interview process. The population of the respondents is all elements within Bina Nusantara University related to the learning process. All respondents can be grouped into three: students, lecturers, and staff. The sampling technique is random sampling for each category of respondents. This brief interview only covers two core questions: 1) What is the most effective learning method? 2) Is the learning method at Bina Nusantara University effective and explained?

The total respondents who are willing to be interviewed are 40 people. The proportion between the three groups of respondents is not balanced. The students' views are the focus in taking the primary data, as shown in Fig. 2.

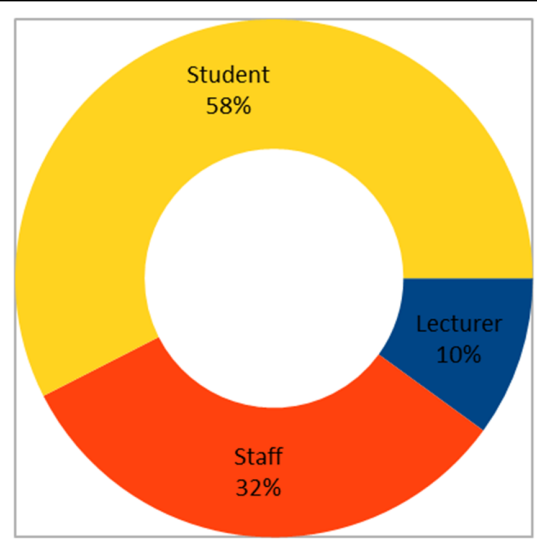

Fig. 2. Respondents' comparison in each category.

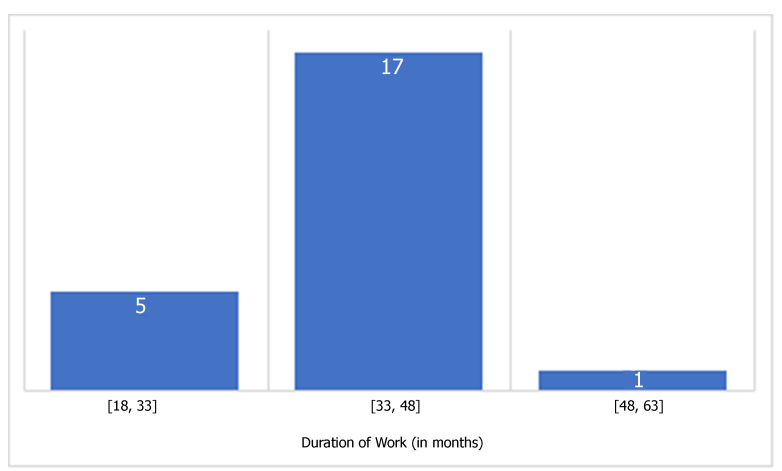

Fig. 3. Histogram of study duration for student respondents (in months).

\section{RESUlTS AND Discussion}

\section{A. The Results of Interview}

More than half of the total respondents are active students who are studying at Bina Nusantara University. The majority of students involved in the primary data collection have been studying for five to eight semesters, as shown in Fig. 3. It is deliberately directed to get completely objective and complete opinions because they are assumed to have to know the pattern of learning methods that they have been using. The yaxis indicates the range of study duration in months. Then, the bar height shows the number of student repondents in the respective range.

In Fig. 4, it can be seen that the student respondents involved in this primary data collection come from five different departments. There are Accounting, Interior Design, Management, Information System, and Information Technology. The largest component of the students comes from Information System as much as $65 \%$.

Meanwhile, for the category of lecturers and employees, most of the respondents are relatively new. 
Cite this article as: T. Febriana and A. Budiarto, "Decision Support System Design Model for Choosing Effective Learning Method in Higher Education Institution", CommIT (Communication \& Information Technology) Journal 15(2), 105-112, 2021.

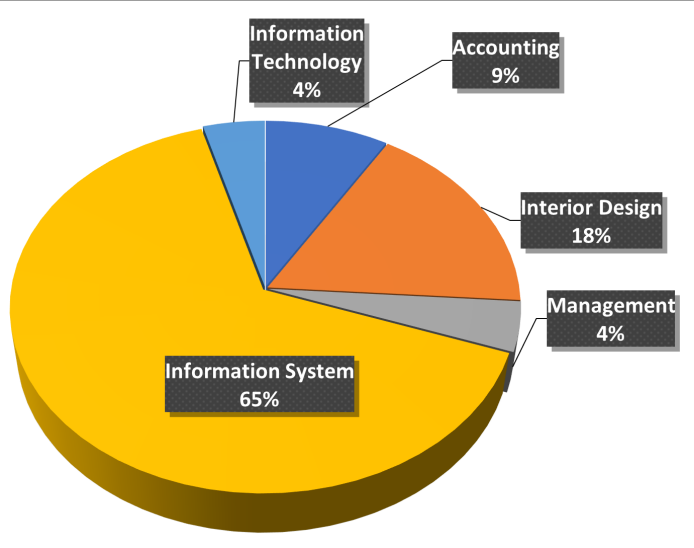

Fig. 4. Categorization of student respondents.

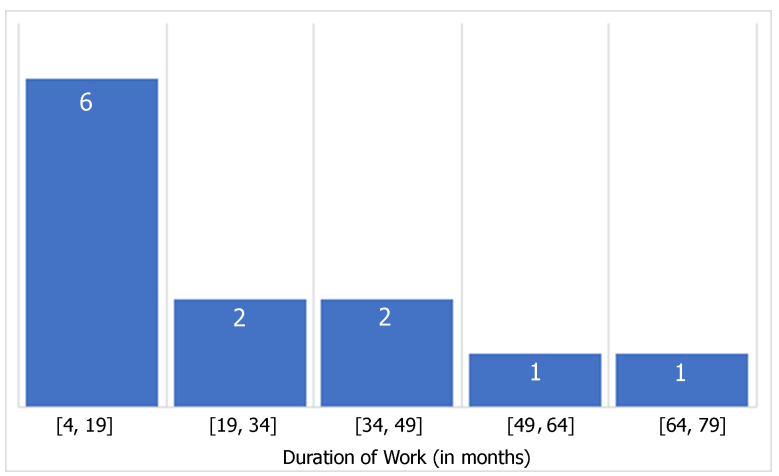

Fig. 5. Histogram of work duration for staff and lecturer (in months).

They have worked less than 20 months. Figure 5 shows the histogram of work duration for staff and lecturers. The $y$-axis indicates the range of work duration, while the bar height shows the number of staff repondents in the respective range.

\section{B. Attributes and Parameters of Decision Making}

The first step in the decision-making process using MCDA is to determine the decision-making attributes. These attributes consist of several stages. Firstly, it is a decision-making goal. In the case of the research, the purpose of the decision-making process based on MCDA is to determine the most suitable learning method to be applied at Bina Nusantara University. Secondly, there are decision-makers. After the purpose of decision-making is determined, it is necessary to determine who is entitled to give opinion or consideration in determining the decision to be taken. In this case, there are three parties to consider: the students as the target of the learning process, the lecturer as the facilitator in the learning process, and the staff who support the learning process. All of these parties will give their views and considerations according to their characteristics and needs. Thirdly, it is decision alternatives. In the decision-making process, it will face several options that must be fully taken into account and considered to finally get the best decision based on the choices and conditions. In determining the most effective learning method, it must first be provided with some choice of learning methods that can be offered to all decision-makers. The choices of learning methods to be offered in this decisionmaking process come from the literature study and the primary data from the interviews conducted. Five learning methods are ultimately made as options in the decision-making process using the MCDA method. These options are personalized learning, project-based learning, place-based education, formative assessment, and maker education.

After the choices that will be chosen as the final decision have been determined, the next step is determining what parameters should be considered in determining the decision. The selection of these parameters also comes from primary data and literature studies that have been done before. The main theory used in the determination of these parameters is Bloom's Taxonomy [20]. In Bloom's Taxonomy, there are six important types of intellectuals in the learning process as follows.

1) Remembering

At this intellectual level, students will be deemed to have successfully performed the learning process if they are succeeded in recalling the information previously provided. In more detail, this type of intelligence can be further divided into the ability to explain, copy, list information, memorize, and recall.

2) Understanding

At this intellectual level means that students can show their understanding of a given fact or theory. This intellectual category consists of the ability to classify information, discuss, report, translate information, and make reports.

3) Applying

At this level, students must be able to apply what is gained from the learning process. This intellectual ability can be translated into the ability to demonstrate learning outcomes, illustrate learning outcomes, interpret, operate, and make the essence based on learning outcomes.

4) Analyzing

The students are deemed to have this intellectual ability if they can compare two phenomena or things of the learning process. In more detail, this intellectual ability can be divided into distinguishing ability, comparative ability, criticism, 
Cite this article as: T. Febriana and A. Budiarto, "Decision Support System Design Model for Choosing Effective Learning Method in Higher Education Institution", CommIT (Communication \& Information Technology) Journal 15(2), 105-112, 2021.

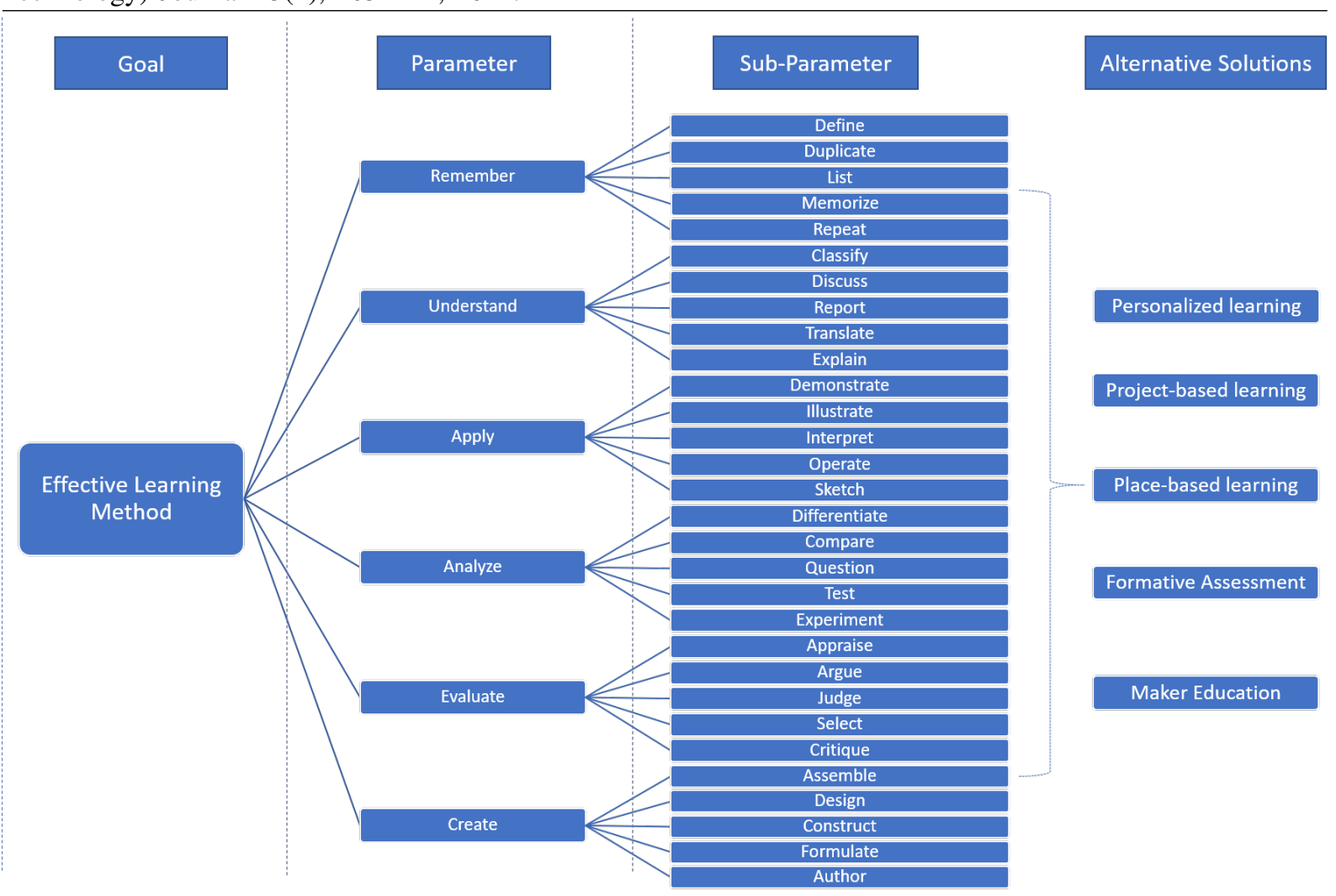

Fig. 6. Multi-Criteria Decision Analysis (MCDA) framework to choose teaching method.

testability, and experimental skills.

5) Evaluating

At this level, students are expected to give an argument from their opinions based on learning outcomes. If this intellectual level is elaborated, it consists of the ability to argue, defend opinions, judge something, choose, and evaluate an idea.

6) Creating

At this level, students must be able to create or produce an idea or a new product that is a derivative of the learning outcomes. Some of the capabilities included in this intellectual category are the ability to build ideas, design something, build new products, create new formulations, and create research.

\section{Framework for Decision Making}

The next step is to create a framework of MCDA based on previously created attributes and decision parameters. This framework is essentially a visualization of all the attributes and parameters of decision-making, as seen in Fig. 6. This framework will be used as a reference in making the MCDA system a tool in making decisions.
TABLE I

THE EXAMPLE OF PARAMETER COMPARISON.

\begin{tabular}{llllllll}
\hline & & A & B & C & D & E & F \\
\hline Remembering & A & X & X & X & X & X & X \\
Understanding & B & B & X & X & X & X & X \\
Applying & C & C & C & X & X & X & X \\
Analyzing & D & D & D & C & X & X & X \\
Evaluating & E & E & E & E & E & X & X \\
Creating & F & F & F & F & F & F & X \\
\hline
\end{tabular}

Then, the researchers create a framework to use to rank out the parameters. Table I can be used as a tool in ranking. Later, all stakeholders who are decisionmakers will use the table to rank. Respondents will be allowed to compare each pair of existing parameters. For example, to remember and understand parameters, the respondents chose to understand. Then, the intersection column between remembering and understanding is labeled "B" as "understand". It is done for all existing parameter pairs until all columns are met. After all the columns are met, the table can be made based on the number of occurrences of each parameter. Table II shows the example of parameter ranking.

After the rank of each parameter is determined, the respondents must fill in the weight for each parameter. 
Cite this article as: T. Febriana and A. Budiarto, "Decision Support System Design Model for Choosing Effective Learning Method in Higher Education Institution", CommIT (Communication \& Information Technology) Journal 15(2), 105-112, 2021.

TABLE II

The EXAmple of PARAmeter RANKING.

\begin{tabular}{lc}
\hline Parameter & Rank \\
\hline Remembering & 0 \\
Understanding & 1 \\
Applying & 3 \\
Analyzing & 2 \\
Evaluating & 4 \\
Creating & 5 \\
\hline
\end{tabular}

TABLE III

THE EXAMPLE OF PARAMETER WeIGHT.

\begin{tabular}{lcc}
\hline Parameter & Rank & Weight \\
\hline Creating & 5 & 40 \\
Evaluating & 4 & 20 \\
Applying & 3 & 15 \\
Analyzing & 2 & 10 \\
Understanding & 1 & 8 \\
Remembering & 0 & 7 \\
Total & & 100 \\
\hline
\end{tabular}

The summed weight of all parameters should be 100, as can be seen Table III. The value in Table III is an example of how to do the parameter weighting to determine which parameter is the most relevant parameter. The higher the rank is, the more relevant the parameter will be.

Then, based on the weight table of each parameter, the next step is to weigh each sub-parameter. For each sub-parameter, the total weight of all sub-parameters in one parameter does not have to be 100 . However, the maximum weight is the weight value of its parameter, as exemplified in Table IV. All the values in Table IV is the example of sub-parameter weighting process. Similar to parameter weighting, the relevancy of each sub-parameter is determined by its weight. The weight indicates the contribution of each sub-parameter to the respective parameter.

The method is to compare all the options that exist based on each sub-parameter. The decision-maker will make a rating, between one to five, for each choice of existing learning methods based on all sub-parameters. Then, the rating will be multiplied by the specified weight. The weights for each sub-parameter will ultimately be used by the decision-maker to determine the final decision. All results of these calculations will be accumulated for each decision option. The greatest value is the final decision of a decision-maker.

The framework and all of its derivative tables will be applied to a web-based application to simplify filling this value. It will be easy for all parties involved to access the required material, whether it is decision choice or decision-making parameter. This model will be used as a reference in making a web-based system as a tool to facilitate decision-makers in formulating
TABLE IV

Sub-Parameter of Weighting Process

\begin{tabular}{|c|c|c|c|}
\hline Parameter & Weight & Sub-Parameter & $\begin{array}{c}\text { Weight of } \\
\text { Sub-Parameter }\end{array}$ \\
\hline \multirow{5}{*}{ Creating } & \multirow{5}{*}{40} & Assemble & 30 \\
\hline & & Design & 10 \\
\hline & & Construct & 20 \\
\hline & & Formulate & 40 \\
\hline & & Author & 15 \\
\hline \multirow{5}{*}{ Evaluating } & \multirow{5}{*}{20} & Argue & 11 \\
\hline & & Appraise & 20 \\
\hline & & Select & 15 \\
\hline & & Judge & 10 \\
\hline & & Critique & 12 \\
\hline \multirow{5}{*}{ Applying } & \multirow{5}{*}{15} & Demonstrate & 15 \\
\hline & & Illustrate & 9 \\
\hline & & Interpret & 13 \\
\hline & & Operate & 10 \\
\hline & & Sketch & 8 \\
\hline \multirow{5}{*}{ Analyzing } & \multirow{5}{*}{10} & Differentiate & 4 \\
\hline & & Compare & 5 \\
\hline & & Question & 9 \\
\hline & & Test & 8 \\
\hline & & Experiment & 10 \\
\hline \multirow{5}{*}{ Understanding } & \multirow{5}{*}{8} & Classify & 7 \\
\hline & & Discuss & 6 \\
\hline & & Translate & 4 \\
\hline & & Explain & 5 \\
\hline & & Report & 8 \\
\hline \multirow{5}{*}{ Remembering } & \multirow{5}{*}{7} & Define & 3 \\
\hline & & Duplicate & 6 \\
\hline & & List & 7 \\
\hline & & Repeat & 5 \\
\hline & & Memorize & 4 \\
\hline
\end{tabular}

the decision to choose effective learning methods for the population at Bina Nusantara University. This system will be built on next year's research.

\section{CONCLUSION}

In an educational institution like higher education, producing qualified graduates is an important priority. However, sometimes universities have difficulty in determining appropriate learning for their students. The determination of this decision requires a tool that can facilitate decision-makers in analyzing all the considerations. Therefore, a tool is needed to facilitate all stakeholders in determining appropriate learning methods by adopting the concept of MCDA.

The researchers have successfully compiled a model of decision-making based on the MCDA method. This model is based on primary data in the form of interviews from 40 respondents consisting of students, lecturers, and staff. In addition, literature studies have also been conducted to enrich the model. The model can become a reference in making a web-based system to choose effective learning methods at Bina Nusantara University for the next year's research.

In this model, some limitations can be used as consideration for further research. The most notable limita- 
Cite this article as: T. Febriana and A. Budiarto, "Decision Support System Design Model for Choosing Effective Learning Method in Higher Education Institution", CommIT (Communication \& Information Technology) Journal 15(2), 105-112, 2021.

tions are those relating to the roles of student, lecturer, and staff in the interview process. Lack of participation from students, lecturers, and staff, results in a lack of direct modeling reference from the parties involved in the learning process. Further research should make this a primary consideration and cooperate with majors or other parties who can collect respondents in large and varied quantities.

\section{REFERENCES}

[1] H. Soetopo, Komponen-komponen dalam pembelajaran. Jakarta: Bumi Aksara, 2016.

[2] M. N. Dudin and Y. S. Shishalova, "Development of effective education and training system in the context of the transition to international accreditation," European Journal of Contemporary Education, vol. 8, no. 1, pp. 118-127, 2019.

[3] D. D. Priya, G. Chavan, K. Thopte, N. Pawar, S. Raut, S. Waghmare, and M. Suji, "Learning styles through Visual, Auditory and Kinesthetic (VAK) scale," European Journal of Molecular \& Clinical Medicine, vol. 7, no. 11, pp. 7925-7932, 2020.

[4] P. Marsden and J. Wright, Handbook of survey research. Bingley, UK: Emerald Group Publishing Limited, 2010.

[5] E. Triantaphyllou and K. Baig, "The impact of aggregating benefit and cost criteria in four MCDA methods," IEEE Transactions on Engineering Management, vol. 52, no. 2, pp. 213-226, 2005.

[6] T. B. Idris, E. Meti et al., "Energy pricing and policies development for geothermal energy in Indonesia," Journal of Renewable Energy and Smart Grid Technology, vol. 11, no. 2, pp. 1726, 2016.

[7] P. Adhikary, P. K. Roy, and A. Mazumdar, "Hydro turbine runner material selection: Application of MCDA or MCDM," in Proc. of FMFP 2016, MNNIT Allahabad, 2016.

[8] H. Zaini, B. Munthe, S. A. Aryani, and R. Rosyad, Desain pembelajaran di perguruan tinggi. Yogyakarta: Center for Staff Development (CTSD) IAIN Sunan Kalijaga, 2002.

[9] B. DePorter, M. Reardon, and S. Singer-Nourie, Quantum teaching: Mempraktikkan quantum learning di ruang-ruang kelas. Bandung: Kaifa, 2002.

[10] E. Turban, J. E. Aronson, and T. P. Liang, Decision support systems and intelligent systems. Pearson/Prentice Hall, 2005.

[11] E. Turban, R. K. Rainer, and R. E. Potter, Introduction to information technology. New York: John Wiley \& Sons, 2001.
[12] V. A. Salomon, P. J. Alonso, and F. A. S. Marins, "Multi-criteria decision analysis of classrooms standardisation in a higher education institution," International Journal of Business and Systems Research, vol. 10, no. 2-4, pp. 394-402, 2016.

[13] B. Talukder, A. Blay-Palmer, K. W. Hipel, and G. W. VanLoon, "Elimination method of MultiCriteria Decision Analysis (MCDA): A simple methodological approach for assessing agricultural sustainability," Sustainability, vol. 9, no. 2, pp. 1-17, 2017.

[14] M. C. Hamilton, J. A. Nedza, P. Doody, M. E. Bates, N. L. Bauer, D. E. Voyadgis, and C. FoxLent, "Web-based geospatial multiple criteria decision analysis using open software and standards," International Journal of Geographical Information Science, vol. 30, no. 8, pp. 16671686, 2016.

[15] E. Triantaphyllou, B. Shu, S. N. Sanchez, and T. Ray, "Multi-criteria decision making: An operations research approach," Encyclopedia of Electrical and Electronics Engineering, vol. 15, no. 1998, pp. 175-186, 1998.

[16] M. M. Köksalan, J. Wallenius, and S. Zionts, Multiple criteria decision making: From early history to the 21st century. World Scientific, 2011.

[17] K. W. Hipel, K. J. Radford, and L. Fang, "Multiple participant-multiple criteria decision making," IEEE Transactions on Systems, Man, and Cybernetics, vol. 23, no. 4, pp. 1184-1189, 1993.

[18] A. Alinezhad and J. Khalili, "MAUT method," in New methods and applications in Multiple Attribute Decision Making (MADM). Springer, 2019, pp. 127-131.

[19] K. D. Goepel, "Implementation of an online software tool for the Analytic Hierarchy Process (AHP-OS)," International Journal of the Analytic Hierarchy Process, vol. 10, no. 3, pp. 469-487, 2018.

[20] S. Masapanta-Carrión and J. Á. VelázquezIturbide, "A systematic review of the use of Bloom's taxonomy in computer science education," in Proceedings of the $49^{\text {th }}$ ACM Technical Symposium on Computer Science Education, 2018, pp. 441-446. 